\title{
Предварительные данные о перемещении береговой линии в районе села Кереть, Северная Карелия
}

Толстобров Д.С. ${ }^{1}$, Вашков А.А. ${ }^{1}$, Колька В.В. ${ }^{1}$, Шелехова Т.С. ${ }^{2}$

${ }^{1}$ Геологический институт КНЦ РАН, Anamumbl, tolstobrov@geoksc.apatity.ru

${ }^{2}$ Институт геологии КарНЦ РАН, Петрозаводск

Аннотация. В работе приведены новые литологические и хронологические данные изучения донных осадков пяти изолированных озерных котловин, расположенных на высотных отметках от 4 до 37 м над современным уровнем моря (н.у.м.) в районе села Кереть, Республика Карелия. В разрезах вскрыты морские и озерные отложения голоцена. Для переходных зон от морского к озерному осадконакоплению выполнялось радиоуглеродное датирование. На основании этих данных построена предварительная кривая перемещения береговой линии Белого моря для района исследования в голоцене.

Ключевые слова: изменение уровня моря, гляциоизостазия, озерные осадки, Белое море, голоцен.

\section{Preliminary data about sea level change near the Keret village, North Karelia}

\author{
Tolstobrov D.S. ${ }^{1}$, Vashkov A.A. ${ }^{1}$, Kolka V.V. ${ }^{1}$, Shelekhova T.S. ${ }^{2}$ \\ ${ }^{1}$ Geological Institute of the KSC of the RAS, Apatity, Russia, tolstobrov@geoksc.apatity.ru \\ ${ }^{2}$ Institute of Geology, Karelian Research Centre, RAS, Petrozavodsk, Russia
}

\begin{abstract}
The article presents new lithological and chronological data from the study of bottom sediments of five isolated basins located at 4.0 to $37.0 \mathrm{~m}$ above sea level (a.s.1.) in the Keret area, Republic of Karelia. The sections reveal sequences of Holocene sediments of marine and lacustrine origin. The sediments formed as a result of the isolation of the lake basin from the sea have been dated. Based on these data, a preliminary sea-level curve for the study area was constructed.
\end{abstract}

Keywords: sea level changes, glacio-isostasy, lake sediments, White Sea, Holocene.

\section{Введение}

Работы по изучению перемещения береговой линии моря в разных частях Фенноскандии проводятся на протяжении более 100 лет (Кошечкин, 1979; Колька и др., 2013а, б; 2014; Лаврова, 1960; Субетто и др., 2012; Corner et al., 1999; 2001; Donner et al., 1977 и др.). В результате для восточной Фенноскандии построено несколько принципиально различающихся схем изобаз поднятий земной коры в позднеледниковье и голоцене (Кошечкин, 1979; Лаврова, 1960), которые отражают блоковый или куполообразный характер воздымания. В данной работе представлены результаты изучения осадков озерных котловин, на побережье Кандалакшского залива Белого моря - вблизи села Кереть (рис. 1). Выполнено стратиграфическое расчленение осадков и реконструировано перемещение береговой линии Белого моря в голоцене. Новые данные позволяют определить характер и скорость поднятия земной поверхности для района исследования.

\section{Район исследования}

В окрестностях села Кереть (Республика Карелия) на небольшом участке побережья (размером $3 \times 3$ км) проведено изучение осадков в пяти озерных котловинах с отметками уровня воды от 4.0 до 37.0 м н.у.м. (рис. 1). Изученные озера занимают небольшие депрессии в пределах эродированной ледником низменности вдоль побережья Белого моря. В районе работ коренные породы повсеместно выходят на поверхность и представлены породами Чупинского парагнейсового пояса и Керетского зеленокаменного пояса с массивами гранитоидов тоналит-трондьемит-гранодиоритовой ассоциации (Слабунов, 2008). Участок находится вблизи юго-западного борта Кандалакшского грабена в зоне оперяющих его разломов (Балуев и др., 2012). 


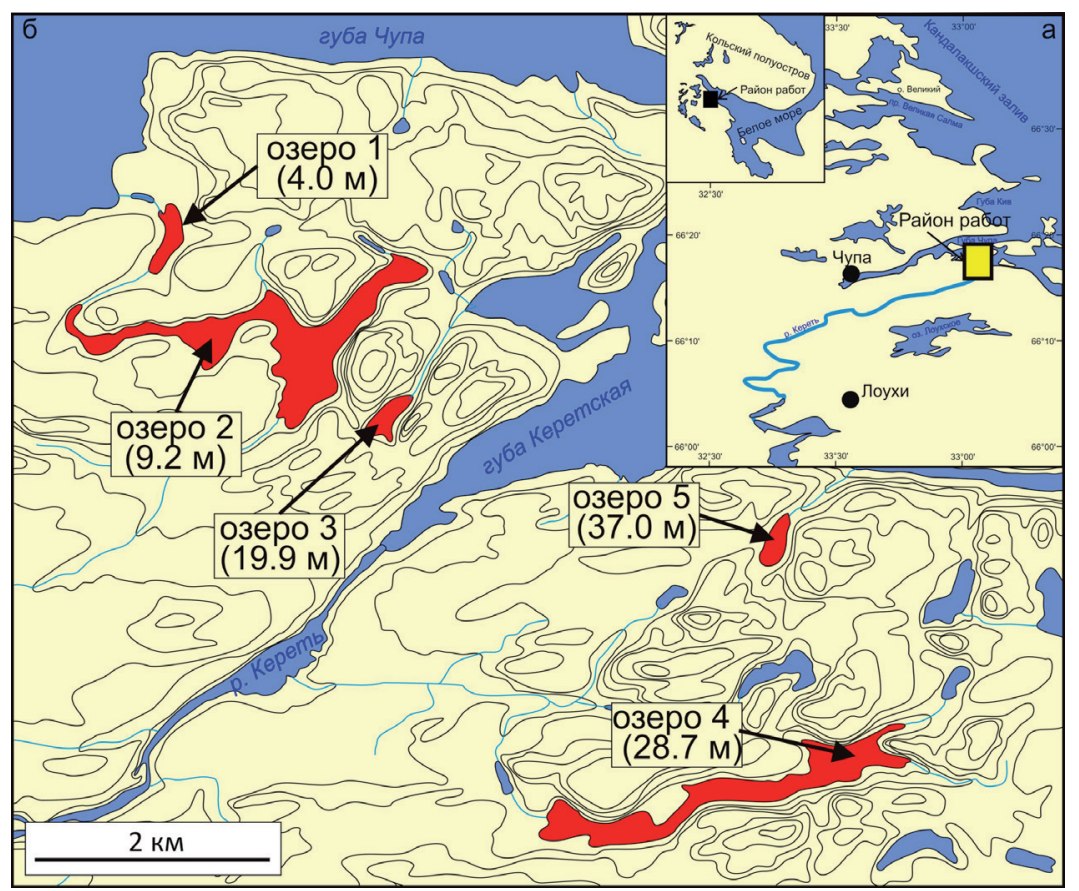

Рис. 1. Положение района исследования (а) и изученных озерных котловин в районе села Кереть (б).

Fig. 1. The location of the study area (a) and of the cored lake basins near Keret area (b).

\section{Методы исследования и материалы}

Для реконструкции относительного перемещения береговой линии моря использован метод изолированных бассейнов (Колька и др., 2013; Corner et al., 1999; Donner et al., 1977 и др.). Метод основан на определении пространственного и временного положения переходной зоны, что позволяет установить где и когда располагалась береговая линия моря.

В ходе полевых работ были исследованы керны донных осадков из пяти озерных котловин (рис. 1 и 2). Отбор кернов выполнялся со льда в самом глубоком, плоскодонном месте озера с помощью «русского торфяного» проотборника. Длина каждого керна составляла 1 м, диаметр 75 мм. В полевых условиях выполнялось литологическое описание и проводилось опробование осадков на микропалеонтологические анализы и радиоуглеродное датирование. Высота порогов стока соответствует высотной отметке поверхности воды в озере, которое определялось по крупномасштабным топографическим картам.

В результате литологического исследования (рис. 2) было выделено три основных фации, отражающие основные условия осадконакопления: фация I - морская (состоящая из минерагенного материала (глина, алеврит, песок), II - переходная (относящаяся к древней береговой линии и состоящая из смешанных органо-минерагенных или органических отложений, обычно слоистых) и III - пресноводное озеро (состоит из гиттии). Во всех изученных озерных котловинах вскрыты регрессивные последовательности, которые включают все три фациальные единицы I - II - III.

В разрезах озер 1 и 2 (рис. 1 и 2) в морских осадках обращает на себя внимание интервал, который сложен алевритами с примесью песка и редкой галькой, обломками раковин мощностью около 10 см. Подобные аккумуляции характерны краткосрочным периодам с повышенной волновой активностью в прибрежной зоне моря и могут быть связаны, в том числе, с катастрофическими событиями (цунами) (Толстобров и др., 2019).

Кривая перемещения береговой линии моря. Результаты исследования донных отложений из озерных котловин позволяют провести модельные построения графика перемещения береговой линии моря в голоцене. Построение осуществляется на основании сведений о характере переходных зон от морских осадков к пресноводным, данных о возрасте этих зон и высоте порогов стока из озер. На оси ординат графика показываются данные о высоте порога стока из озера, на оси абсцисс-дан- 

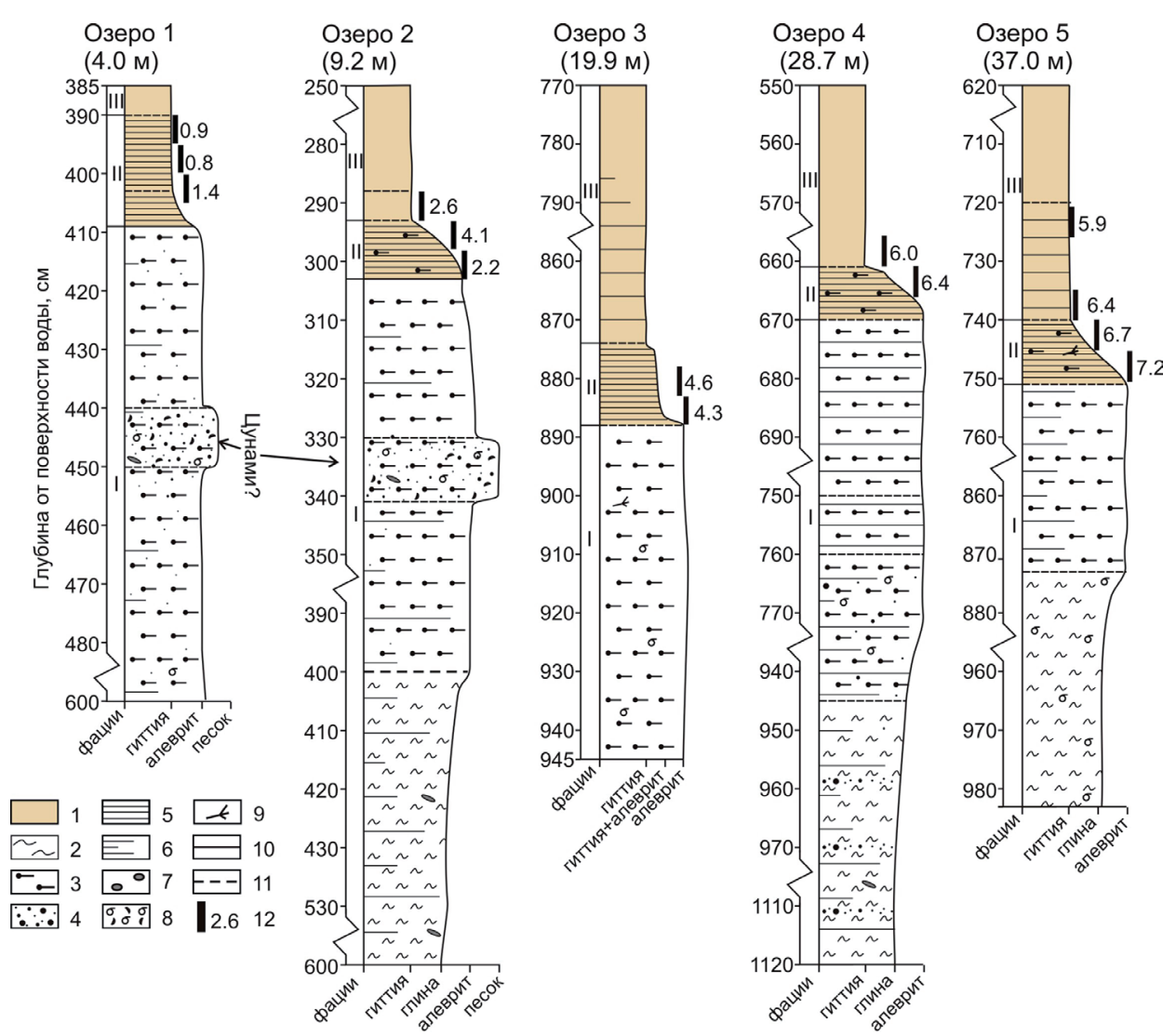

Рис. 2. Разрезы донных осадков озёр, расположенных в районе с. Кереть.

1 - гиттия, 2 - глина, 3 - алеврит, 4 - песок, 5 - слоистость, 6 - неясная слоистость, 7 - гравий/галька, 8 - обломки раковин, 9 - растительные остатки, 10 - резкая граница, 11 - постепенная граница, $12-{ }^{14} \mathrm{C}$ возраст (тысяч кал. лет назад).

Fig. 2. Sections of bottom sediments of lakes located near the Keret area.

1 - gyttja, 2 - clay, 3 - silt, 4 - sand, 5 - lamination, 6 - weak lamination, 7 - gravel / pebble, 8 - fragments of shells, 9 - plant remains, 10 - sharp boundary, 11 - gradual boundary, $12-{ }^{14} \mathrm{C}$ date (thousand cal. a BP).

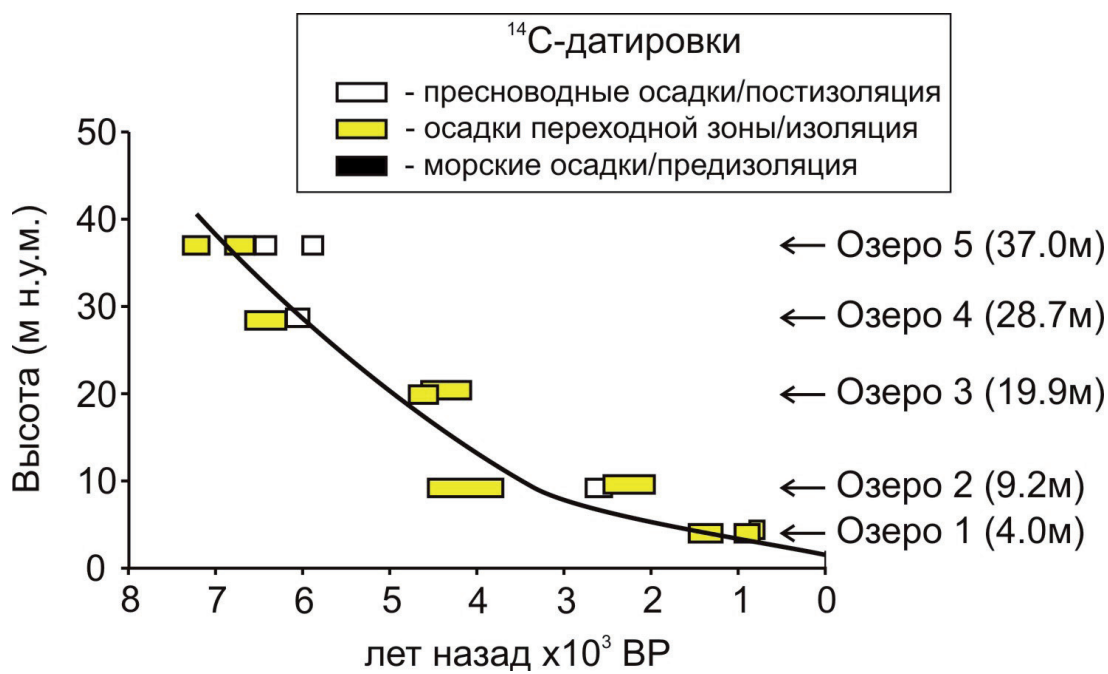

Рис. 3. График изменения относительного уровня моря для района села Кереть, построенный на основании данных датирования изоляционных контактов пяти озерных котловин. Кривая построена для калиброванного возраста.

Fig. 3. Relative sea-level curve for the Keret area based on dated isolation contacts in each of the five investigated lake basins. The curve refers to calibrated years. 
ные о времени изоляции озерной котловины от морского бассейна. Таким образом, результаты изучения серии озер представляют собой точки, при их соединении получается график перемещения береговой линии моря (рис. 3).

Анализ графика показывает, что около 7000 лет назад береговая линия моря в районе исследования находилась на высоте около 37 метров. В течение голоцена происходила регрессия береговой линии моря и соответственно поднятие земной поверхности со средней скоростью примерно 5 мм/год. В настоящее время работы продолжаются: проводится обсуждение полученных данных, выполняются диатомовый, спорово-пыльцевой анализы, поэтому построенный график перемещения береговой линии моря является предварительным и в будущем может быть скорректирован.

\section{Высьоды}

В результате исследования донных отложений озерных котловин с помощью литологических и хронологических методов установлены условия их формирования и выполнена реконструкция перемещения береговой линии Белого моря в районе села Кереть, Северная Карелия. За последние 7000 лет уровень моря в районе исследования понизился на 37 метров, а средняя скорость поднятия территории составила, таким образом, около 5 мм/год. Новые данные дополняют базу данных о положении береговой линии моря в Кандалакшском заливе в голоцене. В дальнейшем эти данные позволят достоверно охарактеризовать вертикальные движения и решить вопрос о дифференцированных вертикальных движениях различных блоков в пределах Кандалакшского грабена, а также позволят реконструировать палеогеографические условия размещения археологических объектов в районе исследования.

Работа выполнена в Геологическом институте КНЦ РАН (тема 0226-2019-0054) при частичной поддержке гранта РФФИ № 18-09-40110-Древности.

\section{Литература}

1. Балуев А.С., Журавлев В.А., Терехов Е.Н., Пржиялговский Е.С. Тектоника Белого моря и прилегающих территорий // Объяснительная записка к «Тектонической карте Белого моря и прилегающих территорий» масштаба 1:1500000. Отв. ред. Леонов М.Г. М. Изд-во: ГЕОС. 2012.

2. Колька В.В., Евзеров В.Я., Меллер Я.Й., Корнер Д.Д. Перемещение уровня моря в позднем плейстоценеголоцене и стратиграфия донных осадков изолированных озер на южном берегу Кольского полуострова, в районе поселка Умба. Известия РАН. Серия геогр. 2013а. № 1. С. 73-88.

3. Колька В.В., Корсакова О.П., Шелехова Т.С. и др. Временная последовательность перемещения береговой линии Белого моря в голоцене по данным изучения донных отложений озер района Кузема (Северная Карелия). Известия РГО. 2014. Т. 146. Вып. 6. С. 14-26.

4. Колька В.В., Корсакова О.П., Шелехова Т.С. и др. Реконструкция относительного положения уровня Белого моря в голоцене на Карельском берегу (район пос. Энгозеро, северная Карелия). ДАН. 2013 б. Т. 449. № 5. С. 587-592.

5. Колька В.В., Корсакова О.П., Шелехова Т.С., Толстоброва А.Н. Восстановление относительного положения уровня Белого моря в позднеледниковье и голоцене по данным литологического, диатомового анализов и радиоуглеродного датирования донных отложений малых озер в районе пос. Чупа (северная Карелия). Вестник МГТУ. Мурманск. Изд-во: МГТУ. 2015. Т. 18. № 2. С. 255-268.

6. Кошечкин Б.И. Голоценовая тектоника восточной части Балтийского щита. Л. Изд-во: Наука. 1979.158 с.

7. Лаврова М.А. Четвертичная геология Кольского полуострова. М.-Л. Изд-во: АН СССР. 1960.234 с.

8. Слабунов А.И. Геология и геодинамика архейских подвижных поясов (на примере Беломорской провинции Фенноскандинавского щита). Петрозаводск. КарНЦ РАН. 2008. 296 с.

9. Субетто Д.А., Шевченко В.И., Лудикова А.В., Кузнецов Д.Д., Сапелко Т.В., Лисицын А.П., Евзеров В.Я., ванн Беек П., Суо М., Субетто Г.Д. Хронология изоляции озер Соловецкого архипелага и скорость современного озерного осадконакопления // ДАН. 2012. Т. 446. № 2. С. 183-190.

10. Толстобров Д.С., Колька В.В., Вашков А.А. Следы катастрофического события в донных осадках озер в районе села Кереть, Карелия // Труды КНЦ РАН. 2019. 6/2019 (10). С. 260-266. DOI: 10.25702/ KSC.2307-5252.2019.6.038.

11. Corner G.D., Yevzerov V. Ya., Kolka V.V., Moller J.J. Isolation basin stratigraphy and Holocene relative sealevel change at the Norwegian-Russian border north of Nikel, northwest Russia // Boreas. 1999. V. 28 . № 1. P. 146-166.

12. Corner G.D., Kolka V.V., Yevzerov V.Ya, Moller J.J. Postglacial relative sea-level change and stratigraphy of raised coastal basins on Kola Peninsula, northwest Russia // Global and Planetary Change. 2001. V. 31. P. $153-175$.

13. Donner J., Eronen M., Jungner H. The dating of the Holocene relative sea-level changes in Finnmark, North Norway // Norsk geografisk Tidsskrift. 1977. V. 31. P. 103-128. 